\title{
(2) OPEN ACCESS \\ Puberty could regulate the effects of outdoor time on refractive development in Chinese children and adolescents
}

\author{
Jingjing Wang (1) ,' Tianyu Cheng, ${ }^{2}$ Bo Zhang, ${ }^{1}$ Shuyu Xiong, ${ }^{2}$ Huijuan Zhao, ${ }^{3}$ \\ Qiangqiang $\mathrm{Li}^{3}{ }^{3}$ Xiangui $\mathrm{He}^{1,2}$
}

\begin{abstract}
- Additional material is published online only. To view, please visit the journal online (http://dx.doi.org/10.1136/ bjophthalmol-2019-315636).

${ }^{1}$ Department of Preventative Ophthalmology, Shanghai Eye Disease Prevention and Treatment Center, Shanghai, China

${ }^{2}$ Department of Ophthalmology, Shanghai General Hospital, Shanghai Jiao Tong University School of Medicine, Shanghai, China

${ }^{3}$ Baoshan Center for Disease Prevention and Control, Shanghai, China
\end{abstract}

\section{Correspondence to} Xiangui He, Shanghai Eye Disease Prevention \& Treatment Center, shanghai 200040, China; xianhezi@163.com

JW and TC contributed equally.

Received 3 December 2019 Revised 8 March 2020 Accepted 30 March 2020 Published Online First 16 April 2020

\section{ABSTRACT}

Aim To explore the impact of puberty on refractive development and its interaction with outdoor time in children and adolescents.

Methods In this 2-year observational study, students aged 7-13 years were selected with cluster sampling. All participants underwent cycloplegic refraction and axial length measurements once every year. Information of related factors was acquired through proper questionnaire or inquiry. The level of testosterone/estradiol was detected from the saliva of the subjects using the ELISA kit. Multiple linear regression and generalised estimating equation (GEE) were used to analyse the relationship among puberty, outdoor activities and refractive indicators.

Results A total of 776 children and adolescents were included, with an average baseline age of $9.64 \pm 1.54$ years and $53.6 \%$ boys. There were 350 myopes (55.2\% of the 634 cyclopleged subjects) at baseline. There was a significant difference in the mean axial length changes and outdoor time among different puberty groups (for axial length: $p=0.017$, for outdoor time: $p=0.015$ ). Myopic parents, less outdoor time and more changes in estradiol were associated with greater changes in axial length and spherical equivalent (SE) (axial length changes: parental myopia $\beta=0.230$, outdoor time $\beta=-0.250$, changes in estradiol $\beta=0.261$; SE changes: parental myopia $\beta=-0.267$, outdoor time $\beta=0.256$, changes in estradiol $\beta=-0.297$ ). In the GEE model, the interaction between outdoor time and puberty was significantly associated with axial length ( $p=0.024, \beta=1.199$ ).

Conclusions This study implies puberty may play a regulating role on the relationship between outdoor time and refractive development among Chinese children and adolescents, which provides clues for in-depth mechanism interpretation and efficient intervention strategies.

\section{INTRODUCTION}

Myopia has become an important public health issue. The rate of myopia among high school students at graduation can reach as high as $80 \%-90 \%$ in some Asian countries. ${ }^{1}$ It is predicted that nearly half of the global population will get myopia by 2050 , and $9.8 \%$ will suffer from high myopia. ${ }^{2}$ Myopia could exert a negative influence on children's quality of life and future career. ${ }^{34}$ The global potential productivity loss associated with visual impairment caused by uncorrected myopia was estimated to be $\$ 244$ billion in $2015 .^{5}$ More seriously, high myopia may even lead to blinding complications. ${ }^{1}$
However, the pathogenesis of myopia has not been clarified yet. The development of myopia is mainly manifested by axial elongation and changes in diopter, which may be caused by the interaction between individual and environmental factors. ${ }^{6-9}$ Outdoor intervention is one of the most effective measures proven to prevent myopia. Meta analysis has corroborated that there was a non-linear relationship between outdoor time and the risk of myopia, generally, an increase of $76 \mathrm{~min}$ outdoors everyday could reduce the risk of myopia by $50 \% .{ }^{10}$ Previous studies suggested that the effect of outdoor time to prevent myopia may be attributed to that outdoor light could influence the release of dopamine and other hormones in the body, especially in the retina, which in turn contribute to myopia prevention. ${ }^{11-14}$

Puberty, important as it is for human growth and development, is the most vigorous period of hormone activity in the body, which has an impact on the synthesis, release, metabolism, as well as transformation of hormones, including dopamine and melatonin, which have been demonstrated to be related to refractive development mechanism. ${ }^{15}$ Several pieces of evidence have demonstrated that there were some correlations between puberty and myopia. ${ }^{1617}$ Another interesting finding was that the effect of outdoor activities on myopia varied at different stages. To be specific, the protective effect of outdoor activities in early puberty $(7-11$ years: $\mathrm{OR}=0.44)$ was stronger than that in other age groups $(11-20$ years: $O R=0.90$, 18-24 years: $\mathrm{OR}=0.94) .{ }^{18-20}$

Therefore, we cautiously speculate that the various ocular components undergo rapid growth and maturation in puberty and are more sensitive to environmental influences, including outdoor activities during this period, which may be regulated by hormones, such as dopamine and melatonin. However, few studies have ever focused on this topic, and the internal relevance among outdoor activity, puberty and refractive development remains unknown. Therefore, the present study aimed to explore the effect of puberty on myopia and its interaction with outdoor activities after adjustment of confoundings. Our findings could hopefully provide references for the study of myopic pathogenesis and formulation of strategies for myopia intervention among children and adolescents.

\section{MATERIALS AND METHODS \\ Study population}

This was a 2-year longitudinal observational study. Cluster sampling was conducted to select eligible 
Table 1 Baseline and follow-up characteristics of the 776 participants by gender

\begin{tabular}{|c|c|c|c|c|}
\hline \multirow[b]{2}{*}{ Variables } & Total $(\mathrm{N}=776)$ & Boys $(n=416)$ & Girls $(n=360)$ & \multirow[b]{2}{*}{ P value* } \\
\hline & \multicolumn{3}{|l|}{ Mean (SD) } & \\
\hline Baseline age (years) & $9.64(1.54)$ & $9.69(1.49)$ & $9.59(1.59)$ & 0.375 \\
\hline $\begin{array}{l}\text { Average daily outdoor } \\
\text { time (hours) }\end{array}$ & $2.04(1.18)$ & $2.06(1.20)$ & $2.01(1.17)$ & 0.548 \\
\hline \multicolumn{5}{|l|}{ Height $(\mathrm{cm})$} \\
\hline Baseline & $143.50(11.17)$ & $144.44(11.40)$ & $142.40(10.80)$ & 0.021 \\
\hline Follow-up & $154.53(15.61)$ & $156.63(14.96)$ & $151.72(17.21)$ & $<0.001$ \\
\hline Changes & $11.03(11.55) \dagger$ & $12.38(8.16) \dagger$ & $9.41(14.44) \dagger$ & 0.001 \\
\hline \multicolumn{5}{|l|}{$\mathrm{AL}(\mathrm{mm})$} \\
\hline Baseline & $24.02(1.13)$ & $24.29(1.10)$ & $23.71(1.08)$ & $<0.001$ \\
\hline Follow-up & $24.64(1.20)$ & $24.91(1.19)$ & $24.32(1.13)$ & $<0.001$ \\
\hline Changes & $0.60(0.33) \dagger$ & $0.60(0.33) \dagger$ & $0.60(0.34) \dagger$ & 0.964 \\
\hline \multicolumn{5}{|l|}{ SE (D) } \\
\hline Baseline & $-1.09(2.00)$ & $-1.17(1.97)$ & $-0.98(2.03)$ & 0.241 \\
\hline Follow-up & $-2.04(2.30)$ & $-2.05(2.35)$ & $-2.02(2.25)$ & 0.880 \\
\hline Changes & $-1.06(0.66) \dagger$ & $-1.05(0.67) \dagger$ & $-1.08(0.64) \dagger$ & 0.563 \\
\hline \multicolumn{5}{|l|}{ Estradiol (pg/mL) } \\
\hline Baseline & $2.79(0.96)$ & $2.70(1.00)$ & $2.92(0.90)$ & 0.063 \\
\hline Follow-up & $4.44(2.58)$ & $4.15(2.38)$ & $4.86(2.79)$ & 0.040 \\
\hline Changes & $1.71(2.82) \dagger$ & $1.56(2.72) \dagger$ & $1.96(2.98) \dagger$ & 0.363 \\
\hline \multicolumn{5}{|l|}{ Testosterone (pg/mL) } \\
\hline Baseline & $51.32(21.86)$ & 54.34 (24.38) & 47.25 (17.18) & 0.006 \\
\hline Follow-up & $81.69(34.05)$ & $93.65(34.95)$ & $64.21(23.69)$ & $<0.001$ \\
\hline \multirow[t]{2}{*}{ Changes } & $33.77(30.45) \dagger$ & $42.68(30.36) \dagger$ & $19.48(24.77) \dagger$ & $<0.001$ \\
\hline & \multicolumn{3}{|l|}{ n (\%) } & P value \\
\hline \multicolumn{5}{|l|}{ Myopia§ } \\
\hline Baseline & $350(55.2)$ & $198(57.2)$ & $152(52.8)$ & 0.262 \\
\hline Follow-up & $343(69.9)$ & $196(69.3)$ & $147(70.7)$ & 0.736 \\
\hline Changes & $73(36.1)$ & $36(32.7)$ & $37(40.2)$ & 0.270 \\
\hline \multicolumn{5}{|c|}{ Menarche/first spermatorrhoea occurrence } \\
\hline Baseline & $83(13.2)$ & $36(10.5)$ & $47(16.3)$ & 0.032 \\
\hline Follow-up & $269(34.7)$ & $78(18.8)$ & $191(53.2)$ & $<0.001$ \\
\hline Changes & $143(26.2)$ & $40(13.1)$ & $103(42.9)$ & $<0.001$ \\
\hline
\end{tabular}

${ }^{*} \mathrm{P}$ value for comparison between boys and girls using a t-test.

$+P<0.01$ for comparison between baseline and follow-up using paired t-test.

$\ddagger \mathrm{P}$ value for comparison between boys and girls using chi-square test.

$\S A$ total of 634 subjects at baseline and 491 subjects at 2-year follow-up participated in the cycloplegic refraction.

$\mathrm{AL}$, axial length; $\mathrm{SE}$, spherical equivalent.

children and adolescents aged 7-13 years at baseline in a 9-year coherent school in Shanghai during 2015-2017. The subjects were examined annually for ophthalmology and collected information on related factors, including outdoor time and puberty. Those with other eye diseases, such as amblyopia, strabismus, blepharoptosis, glaucoma, congenital cataract or severe systemic diseases were excluded from the study.

\section{Data collection}

Axial length was measured by IOL MASTER V.5.02 (Carl Zeiss, Jena, Germany) three times to calculate the average for data analysis. For cycloplegia, one drop of $0.5 \%$ proparacaine hydrochloride and two drops of 1\% cyclopentolate (Alcon, Fortworth, Texas, USA) were instilled in both eyes successively with $15 \mathrm{~s}$ and 5 min intervals. After 25-30 min, eyes were checked for dilation and pupillary response to light. The eye was considered to be cyclopleged if the subject was dilated to $6 \mathrm{~mm}$ or more, without any reaction to light. Autorefraction was performed with an autorefractor (KR-8900; Topcon, Tokyo, Japan) after cycloplegia. Puberty stage was collected by experienced investigators through inquiry. Boys/girls were inspired to recall whether they had first spermatorrhoea/menarche at the time of investigation and to specify the exact time. Menarche or first spermatorrhoea occurrence was chosen as the division of puberty stages, since they are the distinctive signs of the middle puberty, which lasts for 2-3 years. ${ }^{21}$ It can be assumed that subjects with menarche or first spermatorrhoea persistent non-developed (PND) during the 2 years were in the early puberty or prepuberty and those with newly developed (ND) menarche or first spermatorrhoea had entered the middle puberty, while the subjects with menarche or first spermatorrhoea developed at baseline (BD) were in the middle or late puberty. The testosterone/estradiol in the saliva of the subjects gathered by trained investigators was detected using the ELISA kit (German Demartec Diagnostic Company), and the corresponding hormone concentration was read on the standard curve. Each sample was tested three times, and the average value was taken in the final analysis.

Items from Child Vision Care Related Behaviour Assessment Scale compiled by Hui et al was used to collect information on related factors. The questionnaire was confirmed with good reliability and validity, whose Cronbach's coefficient, Guttman split-half coefficient and retest reliability were $0.842,0.610$ and 0.644 , respectively. ${ }^{22}$ The following information was obtained from subjects and their parents, including general information, parental myopia and outdoor activities. Specifically, outdoor activities were gathered by the time spent in daily outdoor leisure, walking and sporting on school and weekend days.
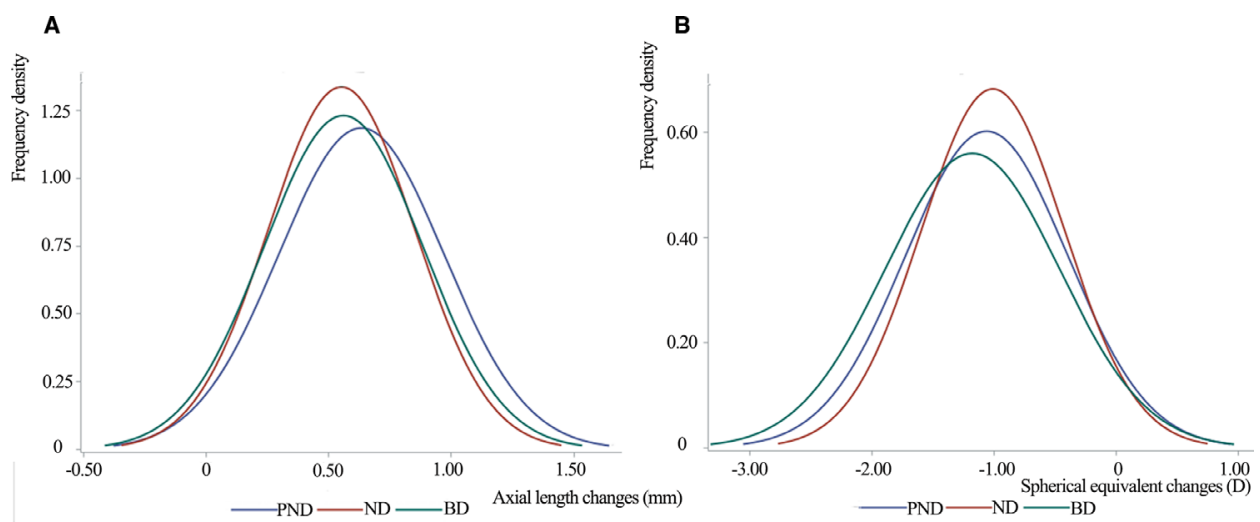

Figure 1 Distribution of changes in ocular parameters among different puberty development groups. BD, baseline developed; ND, newly developed; PND, persistent non-developed. 
Table 2 Changes in ocular parameters and outdoor time among different puberty development groups (mean (SD))

\begin{tabular}{|c|c|c|c|c|c|c|c|}
\hline \multirow[b]{2}{*}{ Puberty development groups } & \multicolumn{3}{|l|}{$\mathrm{AL}(\mathrm{mm})$} & \multicolumn{3}{|l|}{ SE (D) } & \multirow{2}{*}{$\begin{array}{l}\text { Outdoor time } \\
\text { (hours) }\end{array}$} \\
\hline & Baseline & Follow-up & Changes & Baseline & Follow-up & Changes & \\
\hline \multicolumn{8}{|c|}{ Menarche or first spermatorrhoea occurrence } \\
\hline$N D(n=143)$ & $24.24(0.96)$ & $24.79(1.00)$ & $0.55(0.30)^{*}$ & $-1.69(1.98)$ & $-2.86(2.16)$ & $-1.01(0.59)^{*}$ & $2.30(1.29)$ \\
\hline $\mathrm{BD}(\mathrm{n}=83)$ & $24.59(1.21)$ & $25.15(1.24)$ & $0.56(0.32)^{*}$ & $-2.32(2.35)$ & $-3.73(2.44)$ & $-1.18(0.72)^{*}$ & $1.85(1.09)$ \\
\hline$P$ valuet & $<0.001$ & $<0.001$ & 0.017 & $<0.001$ & $<0.001$ & 0.348 & 0.015 \\
\hline$N D(n=40)$ & $24.72(0.97)$ & $25.27(1.07)$ & $0.54(0.33)^{*}$ & $-1.68(1.83)$ & $-2.93(2.00)$ & $-0.96(0.59)^{*}$ & $2.45(1.28)$ \\
\hline $\mathrm{BD}(\mathrm{n}=36)$ & $25.28(1.11)$ & $25.89(1.10)$ & $0.61(0.34)^{*}$ & $-3.12(2.28)$ & $-4.35(2.44)$ & $-1.27(0.81)^{*}$ & $1.92(0.94)$ \\
\hline$P$ valuet & $<0.001$ & $<0.001$ & 0.344 & $<0.001$ & $<0.001$ & 0.187 & 0.072 \\
\hline \multicolumn{8}{|l|}{ Girls' menarche } \\
\hline PND $(n=137)$ & $23.26(0.98)$ & $23.93(1.10)$ & $0.65(0.33)^{*}$ & $-0.20(1.67)$ & $-1.19(1.90)$ & $-1.12(0.69)^{*}$ & $2.06(1.16)$ \\
\hline
\end{tabular}

${ }^{*} P<0.01$, compared between baseline and follow-up within the group using paired t-test.

tStatistical significance was tested using variance analysis.

$A L$, axial length; $B D$, baseline developed; $N D$, newly developed; $P N D$, persistent non-developed; $S E$, spherical equivalent.

\section{Statistical analysis}

The online information system with logic verification was used to collect ophthalmological examination data in real time. Questionnaire data were recorded and reviewed by two independent investigators. SPSS V.24.0 was used for data cleaning and analysis. $\chi^{2}$ test was used to compare rates, while t-test and variance analysis were conducted to compare means among groups. Finally, multiple linear regression (MLR) and generalised estimating equation (GEE) were adopted to explore the association among puberty, parental myopia, outdoor time and refractive indicators after adjustment for age and gender. A $p$ value of $<0.05$ was considered as statistically significant. Only the right eye was included in the analysis. Spherical equivalent $\left(\mathrm{SE}=\mathrm{di}^{-}\right.$ optric degree $+0.5 \times$ cylinder degree $) \leq-0.5 \mathrm{D}$ was diagnosed as myopic.

\section{RESULTS}

\section{General characteristics}

A total of 776 children and adolescents with a mean age of $9.64 \pm 1.54$ years at baseline and $416(53.6 \%)$ boys were enrolled in the present study. At baseline, the mean axial length was $24.02 \pm 1.13 \mathrm{~mm}$ (range from 20.34 to $27.56 \mathrm{~mm}$ ); a total of 634 $(81.7 \%)$ participants agreed to cycloplegic refraction; their mean

A

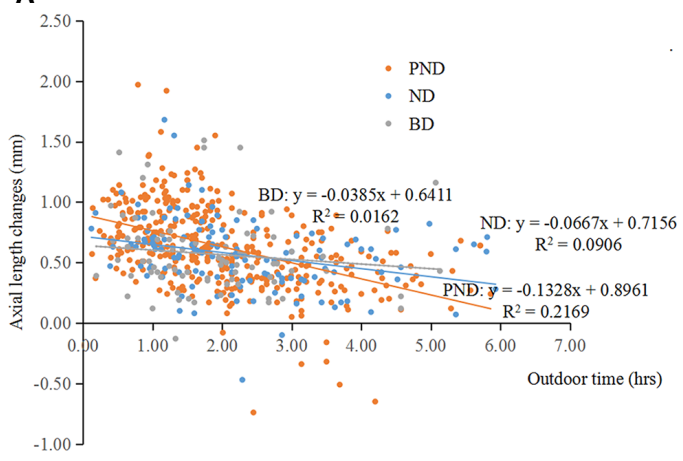

SE was $-1.09 \pm 2.00 \mathrm{D}$ (range from -9.50 to $4.75 \mathrm{D}$ ) and 350 (55.2\%) were myopic. A total of $83(13.2 \%)$ participants had menarche or first spermatorrhoea at baseline. The mean estradiol and testosterone among the subjects were $2.79 \pm 0.96 \mathrm{pg} /$ $\mathrm{mL}$ and $51.32 \pm 21.86 \mathrm{pg} / \mathrm{mL}$. The baseline axial length in boys was longer on average than that in girls $(p<0.001)$, and boys had higher level of testosterone at baseline than girls $(p=0.006)$, while more girls developed menarche than boys developed first spermatorrhoea $(p=0.032)$. No significant difference was observed in baseline SE $(\mathrm{p}=0.241)$ and myopia rate between genders $(\mathrm{p}=0.262)$.

After the 2-year follow-up, there was a significant elongation of the axial length, with a mean change of $0.60 \pm 0.33 \mathrm{~mm}$ (range from -0.74 to $2.84 \mathrm{~mm}$ ) and an average myopic shift of $-1.06 \pm 0.66 \mathrm{D}$ (range from -2.88 to $0.88 \mathrm{D}$ ); the incidence of myopia was $36.1 \%$. The changes in these ocular parameters presented no significant difference between genders. Boys were significantly taller than girls at baseline $(p=0.021)$ and also experienced more changes in height $(p=0.001)$. The average daily outdoor time among the participants was $2.04 \pm 1.18$ hours (range from 0.12 to 5.93 hours), with no significant difference between genders $(p=0.548)$; there were $143(26.2 \%)$ participants with ND menarche or first spermatorrhoea, in which boys

B

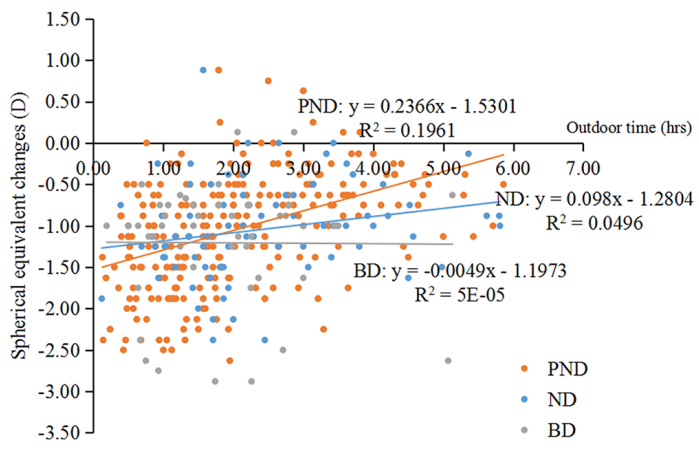

Figure 2 The relationship between outdoor time and changes in ocular parameters among different puberty development groups. BD, baseline developed; ND, newly developed; PND, persistent non-developed. 
Table 3A Multiple regression analysis of factors associated with changes in axial length stratified by puberty development groups

\begin{tabular}{|c|c|c|c|c|c|c|c|c|}
\hline \multirow[b]{2}{*}{ Variables } & \multicolumn{2}{|l|}{ Total } & \multicolumn{2}{|l|}{ PND } & \multicolumn{2}{|l|}{ ND } & \multicolumn{2}{|l|}{ BD } \\
\hline & $P$ value & Standardised $\beta(95 \% \mathrm{Cl})$ & $P$ value & Standardised $\beta(95 \% \mathrm{Cl})$ & $P$ value & Standardised $\beta(95 \% \mathrm{Cl})$ & $P$ value & Standardised $\beta(95 \% \mathrm{Cl})$ \\
\hline $\begin{array}{l}\text { Gender, girls versus } \\
\text { boys }\end{array}$ & 0.993 & $-0.001(-0.083$ to 0.082$)$ & 0.592 & $-0.060(-0.202$ to 0.116$)$ & 0.611 & 0.109 (-0.146 to 0.245$)$ & 0.627 & $-0.244(-0.444$ to 0.275$)$ \\
\hline $\begin{array}{l}\text { Baseline age } \\
\text { (years) }\end{array}$ & 0.183 & $-0.115(-0.074$ to 0.014$)$ & 0.119 & $-0.172(-0.128$ to 0.015$)$ & 0.332 & $-0.168(-0.126$ to 0.043$)$ & 0.099 & $0.359(-0.022$ to 0.232$)$ \\
\hline Parental myopia & 0.001 & 0.230 (0.032 to 0.113$)$ & 0.017 & 0.233 (0.016 to 0.151$)$ & 0.182 & $0.184(-0.025$ to 0.126$)$ & 0.501 & $0.134(-0.071$ to 0.139$)$ \\
\hline $\begin{array}{l}\text { Outdoor time } \\
\text { (hours) }\end{array}$ & $<0.001$ & $-0.250(-0.072$ to -0.022$)$ & 0.017 & $-0.262(-0.103$ to -0.010$)$ & 0.133 & $-0.203(-0.074$ to 0.010$)$ & 0.361 & $-0.174(-0.108$ to 0.041$)$ \\
\hline Estradiol (pg/mL) & 0.189 & $0.091(-0.011$ to 0.057$)$ & 0.858 & $-0.018(-0.062$ to 0.052$)$ & 0.339 & $0.147(-0.039$ to 0.110$)$ & 0.207 & $0.259(-0.030$ to 0.128$)$ \\
\hline $\begin{array}{l}\text { Testosterone (pg/ } \\
\mathrm{mL} \text { ) }\end{array}$ & 0.331 & $0.081(-0.001$ to 0.003$)$ & 0.053 & 0.217 (0 to 0.006$)$ & 0.823 & $-0.040(-0.005$ to 0.004$)$ & 0.805 & $0.058(-0.003$ to 0.004$)$ \\
\hline $\begin{array}{l}\text { Changes in } \\
\text { estradiol ( } \mathrm{pg} / \mathrm{mL})\end{array}$ & $<0.001$ & 0.261 (0.011 to 0.035$)$ & 0.007 & 0.308 (0.009 to 0.050$)$ & 0.077 & $0.273(-0.003$ to 0.050$)$ & 0.866 & $0.030(-0.020$ to 0.024$)$ \\
\hline $\begin{array}{l}\text { Changes in } \\
\text { testosterone (pg/ } \\
\mathrm{mL})\end{array}$ & 0.365 & $0.068(-0.001$ to 0.002$)$ & 0.18 & 0.140 (-0.001 to 0.003$)$ & 0.784 & $0.050(-0.002$ to 0.003$)$ & 0.551 & $-0.135(-0.003$ to 0.002$)$ \\
\hline Height $(\mathrm{cm})$ & 0.236 & $-0.108(-0.008$ to 0.002$)$ & 0.078 & $-0.188(-0.016$ to 0.001$)$ & 0.553 & $0.105(-0.008$ to 0.014$)$ & 0.364 & $-0.296(-0.020$ to 0.008$)$ \\
\hline $\begin{array}{l}\text { Changes in height } \\
(\mathrm{cm})\end{array}$ & 0.003 & $0.278(0.005$ to 0.022$)$ & 0.735 & $0.042(-0.014$ to 0.019$)$ & 0.06 & $0.344(-0.001$ to 0.039$)$ & 0.13 & $0.665(-0.006$ to 0.044$)$ \\
\hline
\end{tabular}

$R^{2}$ for total: $0.445 ; R^{2}$ for PND: $0.567 ; R^{2}$ for ND: $0.375 ; R^{2}$ for $B D: 0.595$

$\mathrm{BD}$, baseline developed; ND, newly developed; PND, persistent non-developed.

Table 3B Multiple regression analysis of factors associated with changes in spherical equivalent stratified by puberty development groups

\begin{tabular}{|c|c|c|c|c|c|c|c|c|}
\hline \multirow[b]{2}{*}{ Variables } & \multicolumn{2}{|l|}{ Total } & \multicolumn{2}{|l|}{ PND } & \multicolumn{2}{|l|}{ ND } & \multicolumn{2}{|l|}{ BD } \\
\hline & $P$ value & $\begin{array}{l}\text { Standardised } \beta \\
(95 \% \mathrm{Cl})\end{array}$ & $P$ value & $\begin{array}{l}\text { Standardised } \beta \\
(95 \% \mathrm{Cl})\end{array}$ & $P$ value & Standardised $\beta(95 \% \mathrm{Cl})$ & $P$ value & $\begin{array}{l}\text { Standardised } \beta \\
(95 \% \mathrm{Cl})\end{array}$ \\
\hline Gender, girls versus boys & 0.417 & $-0.080(-0.335$ to 0.140$)$ & 0.828 & $0.024(-0.344$ to 0.428$)$ & 0.964 & $0.011(-0.612$ to 0.640$)$ & 0.433 & $0.503(-0.836$ to 1.863$)$ \\
\hline Baseline age (years) & 0.533 & $0.058(-0.085$ to 0.163$)$ & 0.283 & $0.118(-0.080$ to 0.270$)$ & 0.394 & $0.168(-0.147$ to 0.365$)$ & 0.985 & $0.004(-0.457$ to 0.465$)$ \\
\hline Parental myopia & $<0.001$ & $\begin{array}{l}-0.267(-0.329 \text { to } \\
-0.101)\end{array}$ & 0.003 & $\begin{array}{l}-0.296(-0.429 \text { to } \\
-0.096)\end{array}$ & 0.195 & $-0.212(-0.394$ to 0.083$)$ & 0.673 & $\begin{array}{l}-0.105(-0.469 \text { to } \\
0.310)\end{array}$ \\
\hline Outdoor time (hours) & 0.001 & $0.256(0.052$ to 0.192$)$ & 0.038 & $0.232(0.007$ to 0.239$)$ & 0.118 & $0.247(-0.028$ to 0.233$)$ & 0.184 & $0.320(-0.094$ to 0.455$)$ \\
\hline Estradiol (pg/mL) & 0.28 & $-0.085(-0.152$ to 0.044$)$ & 0.502 & $-0.071(-0.194$ to 0.096$)$ & 0.835 & $0.039(-0.224$ to 0.276$)$ & 0.816 & $\begin{array}{l}-0.057(-0.313 \text { to } \\
0.250)\end{array}$ \\
\hline Testosterone (pg/mL) & 0.166 & $-0.129(-0.008$ to 0.001$)$ & 0.036 & $\begin{array}{l}-0.237(-0.015 \text { to } \\
-0.001)\end{array}$ & 0.362 & $0.193(-0.008$ to 0.022$)$ & 0.787 & $0.078(-0.011$ to 0.014$)$ \\
\hline Changes in estradiol $(\mathrm{pg} / \mathrm{mL})$ & $<0.001$ & $\begin{array}{l}-0.297(-0.104 \text { to } \\
-0.032)\end{array}$ & 0.001 & $\begin{array}{l}-0.375(-0.155 \text { to } \\
-0.040)\end{array}$ & 0.391 & $-0.155(-0.116$ to 0.047$)$ & 0.42 & $\begin{array}{l}-0.176(-0.112 \text { to } \\
0.049)\end{array}$ \\
\hline Changes in testosterone $(\mathrm{pg} / \mathrm{mL})$ & 0.548 & $-0.050(-0.004$ to 0.002$)$ & 0.149 & $-0.150(-0.008$ to 0.001$)$ & 0.598 & $0.126(-0.006$ to 0.011$)$ & 0.464 & $0.207(-0.006$ to 0.012$)$ \\
\hline Height $(\mathrm{cm})$ & 0.493 & $0.070(-0.010$ to 0.020$)$ & 0.206 & $0.135(-0.007$ to 0.033$)$ & 0.256 & $-0.244(-0.057$ to 0.016$)$ & 0.166 & $0.531(-0.016$ to 0.086$)$ \\
\hline Changes in height $(\mathrm{cm})$ & 0.066 & $-0.190(-0.050$ to 0.002$)$ & 0.555 & $-0.071(-0.052$ to 0.028$)$ & 0.788 & $-0.056(-0.071$ to 0.054$)$ & 0.629 & $\begin{array}{l}-0.214(-0.130 \text { to } \\
0.081)\end{array}$ \\
\hline
\end{tabular}

$R^{2}$ for total: $0.343 ; R^{2}$ for PND: $0.585 ; R^{2}$ for ND: $0.223 ; R^{2}$ for BD: 0.374 .

$\mathrm{BD}$, baseline developed; ND, newly developed in two yrs; PND, persistent non-developed.

were significantly later than girls $(\mathrm{p}<0.001)$. The changes of testosterone in boys were significantly higher than that in girls $(p<0.001)$, while estradiol changes did not show significance $(p=0.363)$. The baseline and follow-up characteristics of the enrolled participants by gender are listed in table 1 .

\section{Changes in ocular parameters and outdoor time among different puberty development groups}

Among the participants, 403 were PND; 143 were ND; and 83 were $\mathrm{BD}$. At baseline, the $\mathrm{BD}$ had longer average mean axial length and greater SE than the ND and the PND both in boys and girls $(p<0.001)$. After 2 years, there was a marked increase in the mean axial length for the PND compared with the ND and $\mathrm{BD}(\mathrm{p}=0.017)$, with an average mean change of $0.63 \pm 0.34 \mathrm{~mm}$ for the PND, and $0.55 \pm 0.30 \mathrm{~mm}$ and $0.56 \pm 0.32 \mathrm{~mm}$ for the
ND and BD, respectively (figure 1A). There was also a significant difference in outdoor time among the three groups, with ND having the longest average time outside. No significant difference was observed in changes of SE among the groups (table 2 and figure $1 \mathrm{~B})$.

\section{Factors associated with longitudinal changes in ocular parameters}

Outdoor time was significantly negatively correlated with changes in the axial length and was significantly positively correlated with changes in SE (all $\mathrm{p}<0.05$, expect for SE changes in the BD: $p=0.964)$. The mean changes in axial length per hour increase in outdoor time were $-0.133,-0.067$ and $-0.039 \mathrm{~mm}$ for the PND, ND and BD, respectively, while the changes in SE were $0.237,0.098$ and $-0.005 \mathrm{D}$ per hour (figure $2 \mathrm{~A}, \mathrm{~B}$ ). 
Table 4A Generalised estimating equation model of factors associated with axial length and SE without interaction

\begin{tabular}{|c|c|c|c|c|}
\hline \multirow[b]{2}{*}{ Variables } & \multicolumn{2}{|l|}{$\mathrm{AL}(\mathrm{mm})$} & \multicolumn{2}{|l|}{ SE (D) } \\
\hline & $P$ value & Estimate $(95 \% \mathrm{Cl})$ & $P$ value & Estimate $(95 \% \mathrm{Cl})$ \\
\hline Age (years) & 0.348 & 1.054 (0.944 to 1.177$)$ & 0.949 & $0.993(0.790$ to 1.247$)$ \\
\hline Girl & $<0.001$ & $0.528(0.415$ to 0.672$)$ & 0.877 & 1.040 (0.635 to 1.702$)$ \\
\hline Boy & - & & - & \\
\hline \multicolumn{5}{|l|}{ Parental myopia } \\
\hline Neither & - & & - & \\
\hline \multicolumn{5}{|c|}{ Menarche or first spermatorrhoea } \\
\hline Occurred & 0.049 & 1.239 (1.001 to 1.536$)$ & 0.003 & 0.514 (0.334 to 0.793$)$ \\
\hline Not occurred & - & & - & \\
\hline Outdoor time (hour) & $<0.001$ & 0.774 (0.701 to 0.854$)$ & $<0.001$ & 1.591 (1.289 to 1.965$)$ \\
\hline
\end{tabular}

$S E$, spherical equivalent; $A L$, axial length.

According to the MLR model, myopic parents, less outdoor time and more changes in estradiol were associated with greater changes in axial length and SE (all $\mathrm{p}<0.05$; for axial length changes: parental myopia $\beta=0.230$, outdoor time $\beta=-0.250$, changes in estradiol $\beta=0.261$; for SE changes: parental myopia $\beta=-0.267$, outdoor time $\beta=0.256$, changes in estradiol $\beta=-0.297)$. Moreover, changes in height were also significantly associated with changes in axial length $(p=0.003, \beta=0.278)$ but insignificantly associated with SE changes $(\mathrm{p}=0.066$, $\beta=-0.190)$. The determination coefficients $\left(\mathrm{R}^{2}\right)$ of the two models were 0.445 and 0.343 , respectively.(table $3 \mathrm{~A}$, table $3 \mathrm{~B}$ ).

When stratified by puberty development groups, parental myopia, outdoor time as well as changes in estradiol remained significantly associated with changes in axial length for the PND (parental myopia: $\beta=0.233$, outdoor time: $\beta=-0.262$ and changes in estradiol: $\beta=0.308$ ), but not for the ND and BD. Factors associated with SE changes demonstrated the same pattern in the three groups (the PND: parental myopia: $\beta=-0.296$, outdoor time: $\beta=0.232$ and changes in estradiol: $\beta=-0.375$ ) (table $3 \mathrm{~A}$ and $3 \mathrm{~B}$ )

\section{Factors in relation to ocular parameters with repeated measurement data using the GEE model}

In the GEE model without interaction, boys, those with two myopic parents, menarche or first spermatorrhoea, less outdoor time and more estradiol had longer axial length (all $\mathrm{p}<0.05$, gender girls vs boys $\beta=0.528$; two myopic parents $\beta=2.214$, menarche or first spermatorrhoea $\beta=1.239$, outdoor time $\beta=0.774$, estradiol $\beta=1.062$ ), while parental myopia, menarche or first spermatorrhoea, outdoor time, estradiol and testosterone were associated with SE (parental myopia: both $\beta=0.220$, either $\beta=0.565$; menarche or first spermatorrhoea $\beta=0.514$; outdoor time $\beta=1.591$, estradiol $\beta=0.912$; testosterone $\beta=0.992$ ).

When interaction item was introduced in the model, no significant correlation was observed between menarche or first spermatorrhoea and the two ocular parameters. However, the interaction between outdoor time and menarche/first spermatorrhoea was significantly associated with axial length, while insignificant in the model of SE (for axial length: $\mathrm{p}=0.024, \beta=1.199$; for SE: $\mathrm{p}=0.473, \beta=0.890$; table $4 \mathrm{~A}$ and $4 \mathrm{~B}$ and figure 3 ). To be specific, the effect of outdoor time on delaying the elongation of axial length was stronger in the PND group than in the ND and BD groups. For different gender groups, the interaction effect remained significant on axial length in girls, while the effect in boys did not show significance (boys: $\mathrm{p}=0.481, \beta=1.108$; girls: $\mathrm{p}=0.019, \beta=1.124$; online supplementary table 1 ).

\section{DISCUSSION}

The present study provided clues on the interaction relationship among puberty, outdoor time and refractive development. The results demonstrated that parental myopia, outdoor time and estradiol were associated with axial length and spherical equivalent changes. Meanwhile, the effect of outdoor time on delaying the elongation of axial length was stronger in early puberty or prepuberty than in the middle and late puberty, suggesting that puberty may play a regulatory role in the process.

Children whose menarche/spermatorrhoea has not occurred were burdened with faster changes in axial length $(p=0.017)$. Interestingly, the effect of different puberty stages on axial length became insignificant $(p=0.448)$, while its interaction with outdoor time was significant in the GEE model $(p=0.024$, $\beta=1.199$ ). Studies on the relationship between puberty parameters and refractive development were limited and drew inconsistent conclusions. A large cross-sectional study in Korea in $2015(n=8398)$ showed that the late onset of menarche was related to the risk of moderate and high myopia (moderate myopia, $\mathrm{OR}=0.93$; high myopia, $\mathrm{OR}=0.85) .{ }^{17}$ An Indian study in 2004 found that the risk of myopia was reduced in those with menarche later than 14 years old $(\mathrm{OR}=0.7) .{ }^{23}$ On the contrary, Yip et al did not find any relationship between menarche and the onset of myopia. ${ }^{16}$ We suppose that the effect of puberty on refractive development is a regulatory effect, which is the result of an interaction between internal individual factors and external environmental factors. Therefore, it only showed weak or insignificant correlations in different studies. When stratified by gender, the interaction effect remained significant in girls $(\mathrm{p}=0.019, \beta=1.124)$, while the effect in boys did not show significance $(p=0.481)$, suggesting that there may be some differences in the pathogenesis of myopia between genders. It is also possible, however, that the sample size of boys entering puberty is insufficient. By contrast, the changes in spherical equivalent did not show significance among puberty groups $(\mathrm{p}=0.348)$, 


\begin{tabular}{|c|c|c|c|c|}
\hline \multirow[b]{2}{*}{ Variables } & \multicolumn{2}{|l|}{$\mathrm{AL}, \mathrm{mm}$} & \multicolumn{2}{|l|}{ SE, D } \\
\hline & $P$ value & Estimate $(95 \% \mathrm{Cl})$ & $P$ value & Estimate $(95 \% \mathrm{Cl})$ \\
\hline Age (years) & 0.273 & 1.062 (0.953 to 1.184$)$ & 0.916 & 0.988 (0.788 to 1.238$)$ \\
\hline \multicolumn{5}{|l|}{ Gender } \\
\hline Girl & $<0.001$ & $0.529(0.417$ to 0.672$)$ & 0.878 & 1.039 (0.635 to 1.701$)$ \\
\hline Boy & - & & - & \\
\hline \multicolumn{5}{|l|}{ Parental myopia } \\
\hline Both & $<0.001$ & 2.203 (1.615 to 3.005$)$ & $<0.001$ & 0.221 ( 0.113 to 0.429$)$ \\
\hline Either & 0.067 & $1.263(0.984$ to 1.622$)$ & 0.030 & $0.569(0.343$ to 0.945$)$ \\
\hline Neither & - & & - & \\
\hline \multicolumn{5}{|l|}{ Menarche or first spermatorrhoea } \\
\hline Occurred & 0.448 & $0.854(0.568$ to 1.284$)$ & 0.278 & 0.653 (0.303 to 1.409$)$ \\
\hline Not occurred & - & & - & \\
\hline Outdoor time (hours) & $<0.001$ & $0.727(0.650$ to 0.813$)$ & $<0.001$ & 1.657 (1.318 to 2.083$)$ \\
\hline Interaction (outdoorxpuberty) & 0.024 & 1.199 (1.024 to 1.403$)$ & 0.473 & 0.890 (0.647 to 1.224$)$ \\
\hline Estradiol (pg/mL) & 0.003 & 1.056 (1.019 to 1.095$)$ & 0.026 & 0.915 (0.846 to 0.989$)$ \\
\hline Testosterone (pg/mL) & 0.165 & 1.003 (0.999 to 1.007$)$ & 0.021 & $0.992(0.985$ to 0.999$)$ \\
\hline Height $(\mathrm{cm})$ & 0.173 & 1.008 (0.997 to 1.020$)$ & 0.604 & 0.996 (0.982 to 1.011$)$ \\
\hline
\end{tabular}

neither did the interaction effect $(p=0.473)$. A possible explanation may be that the changes in crystal refraction compensates for the elongation of axial length in puberty. ${ }^{24}$

Outdoor time had a major role in delaying myopia onset, which has been confirmed in a number of studies. ${ }^{1125-29}$ It was further verified in our study that the effect of outdoor time on myopia shift varied at different puberty stages. More concretely, the mean changes in axial length per hour increase in outdoor time at early puberty or prepuberty were greater than those at middle or late puberty. The mechanism underlying this deserves further exploration. Rose et al suggested that the effect of outdoor time may be due to outdoor light and could influence the level of dopamine in the retina, which has been proven to inhibit axial growth. ${ }^{11}$ It has been observed in animal experiments that light intensity greater than 15000 lux could increase the release of dopamine and slow down the occurrence of myopia in chicken and non-human primate models. ${ }^{30}$ Puberty is the period during which hormone activity including dopamine is affected, thus regulating the effect of outdoor activity on preventing myopia. ${ }^{15}$ However, in spite of the effect of outdoor on myopia prevention in puberty, the average outdoor time for the PND group in our study was 2.01 hours per day; $57.9 \%$ subjects did not reach the

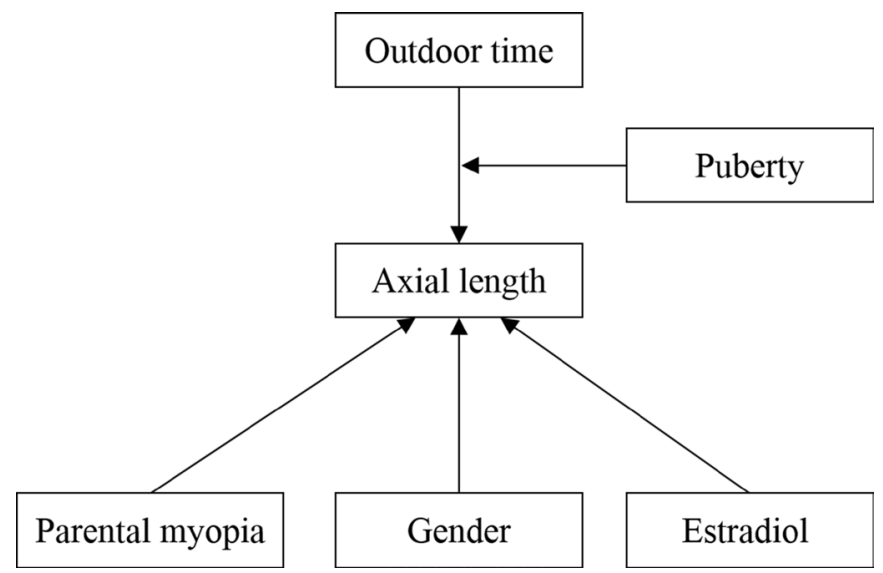

Figure 3 Relationship among outdoor time, puberty and axial length. recommended daily outdoor time,${ }^{11}$ indicating that the outdoor intervention should be strengthened in the early stage of puberty.

Another important finding was that the changes in estradiol was significantly associated with axial length $(\mathrm{p}=0.003, \beta=1.056)$ or spherical equivalent $(\mathrm{p}=0.026, \beta=0.915)$, and testosterone with spherical equivalent $(\mathrm{p}=0.021, \beta=0.992)$. The results may partially answer the question raised by Lyu et al whether the association between puberty and myopia could be attributed to the relationship between hormones and ocular parameters. ${ }^{17}$ Similarly, Xie et al found the level of estradiol, testosterone, follicle stimulating hormone and luteinising hormone were significantly different in myopia and non-myopia groups. ${ }^{31}$ The experiments confirmed that there were sex hormone receptors in the human lacrimal gland, ciliar, lens, retina and other eye tissues. ${ }^{32}$ Besides, the broad range of estrogen-induced proteins was also found in human eye tissues. ${ }^{33}$ These proteins may be coexpressed with oestrogen receptors and thus, produce a marked effect in the development of ocular parameters.

The limitations of this study should be acknowledged when interpreting the results. First, questionnaires were used to collect information on outdoor time. Despite of the possible recall bias, acceptable reliability and validity were confirmed for the questionnaires, and our follow-up research is trying to objectively collect outdoor time using wearable devices. Besides, menarche or spermatorrhoea occurrence did not provide enough information on puberty stages. However, it is more pronounced in external manifestation than other puberty indicators, which can reduce subjective bias to some extent. Finally, the number of cyclopleged subjects was limited during the 2 years, which may reduce the power of the test, causing insignificance in the relationship between outdoor time and spherical equivalent changes among different puberty groups.

In conclusion, our study suggested that outdoor time exerted a function on delaying refractive development, especially in early puberty stage, the hormone level in the body may be involved in the regulation process. Despite that, outdoor time was inadequate in children and adolescents at early puberty. Therefore, attention should be paid to strengthen outdoor time for children especially at early puberty or prepuberty stages. Besides, regular refractive examination and eye health education could also be 
properly performed among children and adolescents with precocious puberty for early intervention measurement to prevent the progression of myopia.

Contributors The study concept and design was conceived by XH. JW, BZ, HZ and QL recruited, screened and obtained consent from the participants and collected information on related factors, including outdoor time and puberty stages. TC and SX conducted the optical examination. JW prepared the first draft of the manuscript. TC, $\mathrm{BZ}, \mathrm{SX}, \mathrm{HZ}, \mathrm{QL}$ and $\mathrm{XH}$ all provided edits and critiqued the manuscript for intellectual content.

Funding This work is supported by the National Natural Science Foundation of China (grant number 81402695) and the Municipal Human Resources Development Program for Outstanding Young Talents in Medical and Health Sciences in Shanghai (grant number 2017YQ019). The funding organisation had no role in the design or conduct of this research.

Competing interests None declared.

Patient consent for publication Not required.

Ethics approval The research followed the tenets of the Declaration of Helsinki and was approved by the ethics committee of Shanghai General Hospital. The number of the approval is 2015KY148. Informed consent was obtained from the subjects and their guardians after an explanation of the nature and possible consequences of the study.

Provenance and peer review Not commissioned; externally peer reviewed.

Data availability statement Data are available upon reasonable request. The data used to support the findings of this study are available from the corresponding author upon request.

Open access This is an open access article distributed in accordance with the Creative Commons Attribution Non Commercial (CC BY-NC 4.0) license, which permits others to distribute, remix, adapt, build upon this work non-commercially, and license their derivative works on different terms, provided the original work is properly cited, appropriate credit is given, any changes made indicated, and the use is non-commercial. See: http://creativecommons.org/licenses/by-nc/4.0/.

\section{ORCID iD}

Jingjing Wang http://orcid.org/0000-0003-2279-9514

\section{REFERENCES}

1 Morgan IG, Ohno-Matsui K, Saw S-M. Myopia. Lancet 2012;379:1739-48.

2 Holden BA, Fricke TR, Wilson DA, et al. Global prevalence of myopia and high myopia and temporal trends from 2000 through 2050. Ophthalmology 2016;123:1036-42.

3 Rose K, Harper R, Tromans C, et al. Quality of life in myopia. Br J Ophthalmol 2000;84:1031-4.

4 Shapiro A, Stollman EB, Merin S. Myopia and career choice. Ann Ophthalmol 1982;14:1156-8.

5 Naidoo KS, Fricke TR, Frick KD, et al. Potential lost productivity resulting from the global burden of myopia: systematic review, meta-analysis, and modeling. Ophthalmology 2019;126:338-46.

6 Ramamurthy D, Lin Chua SY, Saw S-M. A review of environmental risk factors for myopia during early life, childhood and adolescence. Clin Exp Optom 2015;98:497-506

7 Morgan I, Rose K. How genetic is school myopia? Prog Retin Eye Res 2005;24:1-38.
8 Mutti DO, Mitchell GL, Moeschberger ML, et al. Parental myopia, near work, school achievement, and children's refractive error. Invest Ophthalmol Vis Sci 2002;43:3633-40.

9 Low W, Dirani M, Gazzard G, et al. Family history, near work, outdoor activity, and myopia in Singapore Chinese preschool children. Br J Ophthalmol 2010;94:1012-6.

10 Xiong S, Sankaridurg P, Naduvilath T, et al. Time spent in outdoor activities in relation to myopia prevention and control: a meta-analysis and systematic review. Acta Ophthalmol 2017:95:551-66.

11 Rose KA, Morgan IG, Ip J, et al. Outdoor activity reduces the prevalence of myopia in children. Ophthalmology 2008;115:1279-85.

12 Zhang J, Deng G. Protective effects of increased outdoor time against myopia: a review. J Int Med Res 2019;40:030006051989386.

13 Cohen $\mathrm{Y}$, Peleg $\mathrm{E}$, Belkin $\mathrm{M}$, et al. Ambient illuminance, retinal dopamine release and refractive development in chicks. Exp Eye Res 2012;103:33-40.

14 Chakraborty R, Ostrin LA, Nickla DL, et al. Circadian rhythms, refractive development, and myopia. Ophthalmic Physiol Opt 2018:38:217-45.

15 Sizonenko PC. Physiology of puberty. J Endocrinol Invest 1989;12:59-63.

16 Yip VC-H, Pan C-W, Lin X-Y, et al. The relationship between growth spurts and myopia in Singapore children. Invest Ophthalmol Vis Sci 2012;53:7961-6.

17 Lyu IJ, Kim MH, Baek S-Y, et al. The association between menarche and myopia: findings from the Korean National health and nutrition examination, 2008-2012. Invest Ophthalmol Vis Sci 2015;56:4712-8.

18 Lee Y-Y, Lo C-T, Sheu S-J, et al. Risk factors for and progression of myopia in young Taiwanese men. Ophthalmic Epidemiol 2015;22:66-73.

19 Dirani M, Tong L, Gazzard G, et al. Outdoor activity and myopia in Singapore teenage children. Br J Ophthalmol 2009:93:997-1000.

20 Wu P-C, Tsai C-L, Wu H-L, et al. Outdoor activity during class recess reduces myopia onset and progression in school children. Ophthalmology 2013;120:1080-5.

21 Chengye J. Modern children and adolescents hygiene. People's Medical Publishing House, 2010

22 HWL Tet al. Development, reliability and validity of child vision care related behavior assessment scale. Chinese School Health 2009;11:1007-10.

23 Nirmalan PK, Katz J, Robin AL, et al. Female reproductive factors and eye disease in a rural South Indian population: the Aravind comprehensive eye survey. Invest Ophthalmol Vis Sci 2004;45:4273-6.

24 Brown NP, Koretz JF, Bron AJ. The development and maintenance of emmetropia. Eye 1999:13 (Pt 1:83-92.

25 Jones LA, Sinnott LT, Mutti DO, et al. Parental history of myopia, sports and outdoor activities, and future myopia. Invest Ophthalmol Vis Sci 2007:48:3524-32.

26 French AN, Ashby RS, Morgan IG, et al. Time outdoors and the prevention of myopia. Exp Eye Res 2013;114:58-68.

27 He M, Xiang F, Zeng Y, et al. Effect of time spent outdoors at school on the development of myopia among children in China: a randomized clinical trial. JAMA 2015:314:1142-8.

28 Sherwin IC, Reacher MH, Keogh RH, et al. The association between time spent outdoors and myopia in children and adolescents: a systematic review and metaanalysis. Ophthalmology 2012;119:2141-51.

29 French AN. Increasing children's time spent outdoors reduces the incidence of myopia. Evid Based Med 2016;21:76.

30 Norton TT, Siegwart JT. Light levels, refractive development, and myopia--a speculative review. Exp Eye Res 2013;114:48-57.

31 Xie H, Mao X, Yang H, et al. [Analysis on the relationship between adolescent myopia and serum sex hormone]. Zhonghua Yi Xue Za Zhi 2014;94:1294-7.

32 Wickham LA, Gao J, Toda I, et al. Identification of androgen, estrogen and progesterone receptor mRNAs in the eye. Acta Ophthalmol Scand 2000;78:146-53.

33 Gupta PD, Johar K, Nagpal K, et al. Sex hormone receptors in the human eye. Surv Ophthalmol 2005:50:274-84. 